\title{
FMEA TECHNIQUES USED IN ENVIRONMENTAL RISK ASSESSMENT
}

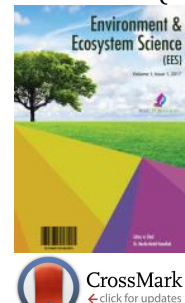

Soghra Vazdani*1, GHolamReza Sabzghabaei ${ }^{2}$, Soolmaz Dashti ${ }^{3}$, Mitra Cheraghi' ${ }^{4}$, Reza Alizadeh ${ }^{5}$, Aazam Hemmati ${ }^{6}$

${ }^{1}$ Khatam Alanbia University of Technilogy Behbahan graduate student in environmental pollution, Behbahan, Iran.

${ }^{2}$ Assistant Professor, Departmen of Environment,Behbahan Khatam Alanbia University of Technology, Behbahan, Iran.

${ }^{3}$ Assistant Professor,Departmen of Environment, Ahvaz Branch Islamic Azad University, Ahvaz, Iran.

${ }^{4}$ P.h. D student environment, Tarbiat Modarres University.

${ }^{5}$ Assistant Professor, Departmen of Environment,Behbahan Khatam Alanbia University of Technology, Behbahan, Iran.

${ }^{6}$ Environmental Expert, Parsian gas refinery.

*Corresponding author email: s.vazdani3071@gmail.com

This is an open access article distributed under the Creative Commons Attribution License, which permits unrestricted use, distribution, and reproduction in any medium, provided the original work is properly cited.

\section{ARTICLE DETAILS}

Article History:

Received 6 July 2017

Accepted 9 October 2017

Available online 5 November 2017

Keywords:

Assessment,

FMEA, environmental, failure

modes.

\section{ABSTRACT}

Other industries or strategic installations cities after the industrialization process, a large percentage of urban land use, consciously or unconsciously to have been allocated. Investigation and detection of black spots and dangerous in systems and processes to prevent accidents is of particular importance. Risks in the project, are unknown events that may happen in the event of a negative or positive impact on project objectives is effective. Each event has specific causes and consequences are distinguishable. The consequences of these events directly in time, cost and quality. Therefore, effective project risk identification and to determine the effect of special importance. Organizations should be able to use a variety of methods to assess the risk of one or a combination of the select few. This article introduces the risk assessment and FMEA methodology has been focused on the process of doing that.

\section{INTRODUCTION}

Industrial applications or strategic installations After the industrialization process of cities, they have been consciously or unknowingly responsible for a large percentage of urban utilities. In the event of accidents, such consequences as explosion, fire and other related incidents have been caused by collateral applications and have increased the magnitude of urban destruction and human casualties, in particular, this use with residential homes, Hospitals, and schools, and may endanger the human nature by introducing new threats and endangering human environments [1]. Environmental contamination is a minor and unintended product of various industrial activities that has caused the environment to become more threatened [2]. Today, environmental crises, the move towards sustainable development, the removal of non-tariff barriers to the economy, the prevention of waste and waste of resources, and the creation of conditions for understanding tariffs and economic issues can be among the causes. Environmental management systems [3]. In this view, the coordination of quality, environmental, safety and health promotion is the criterion for choosing services and products in a civilized human society [4]. Therefore, the management of the organization should be based on safety and environmental protection and quality should be considered as the main axis of each organization and the establishment of such a system should be considered by the proper planning and proper recognition of these systems. So far, various methods have been used to identify, classify, and evaluate risk. The method of analysing the failure scenarios and its effects is one of these methods, which is itself a new method of evaluation and risk management in oil and petrochemical industries [5]. The assessment of environmental risk, the process of qualitative analysis of potential risks and the coefficient of actualization of the potential risks in the project as well as the sensitivity or vulnerability of the perimeter environment. Accordingly, in addition to studying and analysing various aspects of risk, with the full knowledge of the environment of the region, the sensitivity of the environment is affected, as well as the environmental values of the region in the risk analysis [6]. The main purpose of the analysis and evaluation of risk is to determine the degree of uncertainty of the studied system and its cost and provide solutions for its reduction as well as the cost of the cost of the corresponding solution [7]. The method of analysing the failure states and its effects on the environment Biology is a qualitative assessment method for environmental impacts that aims to provide a tool for facilitating the work of companies, so that the development of production is considerably Environment [8]. Among the risk assessment techniques, the FMEA methodology is the only analytical method in risk assessment that can better assess the potential risks in the range and also identify the causes and effects associated with it, and rank the advantages of this method can be the appropriateness of the quantitative risk assessment and the reliability of this method for predicting problems and identifying the most effective risk prevention solution [8].

\section{RISKS AND DANGERS}

The term risk has several definitions. When we look at the definitions, we find that each of the researchers has, at the present time, put forward a specific definition of their own, by giving reasons and broad discussions. Risk refers to all potential parameters that could pose a threat to process, system or project safety. Risk is the diversion of occurrences that can occur over a given period at a given location. Therefore, risk is known as the probability of occurrence or non-occurrence of the event and its risks [9].

\section{RISK ASSESSMENT}

Risk assessment of risks and attention to its ability to withstand personnel, facilities and the environment usually involves identifying initiating events, identifying probable sequences of incidents, estimating the probability of occurrence of accident sequences and evaluating the outcomes. Then, based on the appropriate criteria for the situation, the risk is acceptable and judged. When assessing risk, attention is paid to the likelihood of occurrence and the severity of the consequences of a dangerous initiator event. Based on the assessment of risks and risks and in order to achieve a tolerable level of risk, recommendations for risk reduction should be provided as needed. These recommendations can be based on an analyst's judgment, or on the basis of criteria chosen by the company to guide decision-making on risk reduction [10]. 


\section{ASSESSMENT AND MANAGEMENT OF ENVIRONMENTAL RISK}

This issue has been emphasized as one of the main elements of the safety, health and environment management system, under the title of Risk Assessment and Management [11]. The first step in the process of managing and evaluating risk is to identify the risks and their effects. Risk assessment and management, with the aim of identifying and assessing hazards to find corrective strategies for preventing incidents, is an important and vital task [12]. Today, the effects of environmental hazards have been a source of concern for a few. In recent decades, consideration of the environmental consequences of plans and plans and the risk associated with its occurrence have been considered by politicians in different ways. One of the most important issues in this area is the environmental risk assessment that can be used as an appropriate tool for investigating the effects of human activities on the environment.

Environmental risk assessment, the quantitative and qualitative analysis of risk potentials and the coefficient to be applied to the potential risks in the project, as well as the sensitivity or vulnerability of the peripheral environment. The various steps of the environmental risk assessment process include risk identification and analysis, exposure assessment, risk estimation, risk assessment and risk management. So far, most of the studies conducted in our country and other countries in the world have focused on the safety aspects of projects, and less have been addressed to their environmental aspects. Environmental risk assessment can be used as an integral part of the assessment of environmental impacts [13].

\section{STEPS TO RISK ASSESSMENT}

Risk assessment is done to determine the severity of the impact of the hazards in the process. By deciding whether the adverse effects of such events are such that it needs to be completely eliminated or only sufficient control and prevention is made, the risk assessment will determine the existing risks and prioritize them in the process of risk management, how should they be treated first. In order to assess the risk of industrial units, the stages often follow the diagram below [14].

\section{RISK ASSESSMENT USING THE FMEA METHOD}

Failure mode and impact analysis (FMEA) is a systematic method for analysing and ranking the hazards associated with different products or processes and prioritizing hazards to propose appropriate corrective actions and achieve a desirable situation $[15,16]$. The Failure and Its Effect Analysis (FMEA) technique was originally used for systematic analysis of the failure modes of development and its subsequent effects on Défense products specifically used in the aviation sector [17]. This technique was used to analyse the failure mode of nuclear, automotive, chemical, and mechanical products. Over time, the FMEA technique was widely used in the analysis of errors in service industries such as the software industry $[18,19,9,20]$. The main purpose of using the FMEA method is to identify the potential fail system states of the system, evaluate its causes and effects on the system, provide a solution to eliminate or reduce the likelihood of occurrence and severity of its effect. Calculates the degree of failure mode using the Risk Priority Number (RPN). RPN is derived from three components: severity of risk (S), probability of occurrence of risk (P) and risk of detection (D). The RPN number prioritizes the failure modes of a product or system so that the higher the RPN is, the more defective the more dangerous and more resources are allocated in terms of time and cost. In which the risk parameters $\mathrm{P}, \mathrm{S}$, and $\mathrm{D}$ are obtained using the Likert scale [21].

The identified environmental aspects are evaluated using FMEA risk assessment methodology. A checkerboard is designed to evaluate the environmental degradation factor. This checklist includes variables such as process identification, potential failure mode (environmental aspects), potential effects of failure (consequences), potential failure causes, initial assessment of environmental aspects (severity, occurrence, extent of contamination, RPN or Risk level (control action) and secondary assessment of environmental aspects (severity, occurrence, extent of contamination, RPN or risk level) as environmental aspects. Since the checklist has content validity, this checklist is set up with the participation and views of professional health professionals, HSE, environmentalists and other experts based in the unit.

After collecting the necessary information, the environmental degradation factor was evaluated by analyzing the failure states and its effects on the environment-environment (EFMEA). Accordingly, the desired RPN is calculated from the multiplication of the three parameters of the rank of severity, probability of occurrence and the extent of the contamination. The way to score is that for the "intensity" parameter, the number is scored between 1 and 5 , so that in the extreme case, the score is 5 , and in the lowest case, the score is 1 to the desired parameter. Also, the probability of occurrence is also the number between 1 and 5 to the desired parameter. In the highest and lowest cases, the probability of occurrence was ranked by numbers 1 and 5 respectively. In the case of the "polluter" parameter, the range of 1 to 5 modes will be monitored, with the highest score of 5 and the lowest score of 1 [22].

Table 1: Extent of the environmental aspect

\begin{tabular}{|c|c|}
\hline Rating & Criterion \\
\hline 5 & Pollution outside of site \\
\hline 4 & The entire site is contaminated \\
\hline 3 & Pollution is a large part of the site \\
\hline 2 & Infection is a small part of the site \\
\hline 1 & Indispensable Contamination \\
\hline
\end{tabular}

Table 2: The probability of occurrence of the environmental aspect

\begin{tabular}{|c|c|}
\hline Rating & Criterion \\
\hline 1 & Once a month or less \\
\hline 2 & How many times in month \\
\hline 3 & How many times in the week \\
\hline 4 & Once upon a time \\
\hline 5 & Continuous \\
\hline
\end{tabular}

Table 3: The severity of environmental impacts

\begin{tabular}{|c|c|}
\hline Rating & Criterion \\
\hline 1 & Very little impact \\
\hline 2 & $\begin{array}{c}\text { Environmental impacts / slight disturbance or } \\
\text { slight discomfort }\end{array}$ \\
\hline 3 & $\begin{array}{c}\text { Average environmental impacts / consumption } \\
\text { of natural resources and energy }\end{array}$ \\
\hline 4 & $\begin{array}{c}\text { Significant environmental impacts / harmful } \\
\text { effects on humans and other living organisms / } \\
\text { disruptive equilibrium of ecosystems }\end{array}$ \\
\hline 5 & $\begin{array}{r}\text { Environmental impacts / threats to human life } \\
\text { and other living organisms }\end{array}$ \\
\hline
\end{tabular}

After calculating the obtained RPNs which indicates the environmental degradation factor, the following statistical relationships are used to classify the levels of risk:

The relationship between the calculation of the data arithmetic mean Relation (1)

$$
\bar{x}=\frac{1}{N} \sum_{i=1}^{N} x_{i}=\frac{x_{1}+x_{2}+\cdots+x_{N}}{N}
$$

The ratio of the calculation of standard deviation Relation (2)

$$
\sigma=\sqrt{\frac{1}{N} \sum_{i=1}^{N}\left(x_{i}-\bar{x}\right)^{2}}
$$

\section{$\mathrm{X}=$ Arithmetic average}

$\mathrm{N}=$ number of data

$\mathrm{Xi}=$ Data $(\mathrm{RPN})$

And according to the above relationships, all aspects are classified into three categories with low risk level (L), aspects with medium risk (M) and high-risk $(\mathrm{H})$ aspects. Takes place and proposed corrective and controlling measures for each of them to reduce their risk level [23-25]. 


\section{CONCLUSION}

Researches carried out in the field of environmental management at home and abroad indicate that the use of risk assessment techniques and appropriate risk management and, as a result, environmental risk assessment, can be a deterrent and preventive factor for Environmental hazards. Environmental risk assessment, along with environmental monitoring, will provide useful and complete results to environmental managers. In general, it can be noted that conducting environmental impact assessment studies in identifying environmental degradation factors and impacts, as well as providing solutions for reducing and reducing negative impacts, is very important. In this regard, the evaluation report should have a coherent structure and avoid addressing marginal issues and minimize the underlying issues, and identify the main problems and provide them with executive solutions and apply the actual scores to the experts in the analysis of the effects. To help improve the current situation. In order to properly implement the FMEA method, the following points are considered to be necessary:

1. association and cooperation privates team

2. Create appropriate communication loops for proper use of outputs

3. Provide conditions and resources for change (corrective and preventive measures)

\section{ACKNOWLEDGMENTS}

This research is sponsored by Parsian Gas Refining Company. Thanks to the unparalleled efforts of the Research and Technology Unit, the HSE Unit and the Environmental Centre.

\section{REFERENCES}

[1] Fam, M., and Iraj. 2008. Establishment of the HSE system in the oil industry and its improvement solutions, Workshop and the 4th National Conference on Environmental Ecosystems in Iran, Islamic Azad University, Khouzestan Science and Research Branch.

[2] Shameh, and Maryam. 2008. Planning and management of control and reduction of environmental pollutants in the steel industry to achieve safety, health and environment favorable (Case study: Kavian Steel Co.), Master's Degree, Science and Technology Department Ahwaz research.

[3] Tahomourian, and Farzaneh. 2007. Principles of Environmental Management, First Edition, Fadak Isatias Publishing, 15.

[4] Habibi, Ehsanollah, Alizadeh, Majid. 2007. Applicable Safety Performance Indicators in the Industry, Second Edition, Fanavaran Publishing, 357.

[5] Allen, H.Hu., Hsu, C.W., Kuo, T.C., and Wu, W.C. 2009. Risk evaluation of green components to hazardous substance using FMEA and FAHP. Expert Systems with Applications.,36,7142-7147.

[6] Muhlbauer, W.K. 1999. Pipeline risk management manual, Gulf Professional Publishing, 2an Ed., USA,428.

[7] Gharchurlu, and Najaf. 2005. Evaluation and Management, Science and Technology Publications, First Edition, 204.

[8] Jensen, C., Johansson, M., Lindahl, M., and Magnusson, T. 2001. Environmental Effect Analyysis(EEA)-Principles and structure. Department of Techniligy, University of Kalmar: Kalmar, Sweden.8.

[9] Shawulu, H. N. 2012. Software failure analysis at architecture level using FMEA. International Journal of Software Engineering and its Applications, 6(1), 61-73.
[10] Moradi, Hassan, Sahib, P., Moghdad. 2011. HSE Risk Assessment and Management, Diesel Drilling Machines by William Fein, Oil, Gas, and Energy Monthly, Third Year, No. 11.

[11] Fam, M., Iraj, and Ali, K. 2010. Application of Operational and Risk Study Technique (HAZOP) Assessment of Hazards and Environmental Hazards (A Case Study of Petroleum Storage Depot Oil Company). Environmental Science and Technology, 12th Period, Issue 1.

[12] Exit, and Fereshte. 2009. Presentation of an Applied Model for Assessing the Risk of Oil and Gas Pipelines, Third National Conference on Safety Engineering and HSE Management.

[13] Akbarzadeh, Abbas. 2008. Safety, Health and Environment in Process Industries, Laboratory Research Centre, 576.

[14] Khan, F.I, and Abbasi, S.A. 2002. A criterion for developing credible accident scenarios for risk assessment. Journal of Loss Prevention in process Industries, 15, 467-475.

[15] Barendsa, D.M., Oldenhofa, M.T., Vredenbregta, M.J., and Nautab, M.J. 2012. Risk analysis of analytical validations by probabilistic modification of FMEA. Journal of Pharmaceutical and Biomedical Analysis, 64 (65), 826.

[16] Dailey, K.W. 2004. The FMEA pocket handbook. 1st ed. USA: DW Publishing Co.

[17] Bowles, J. B., and Peláez, C. E. 1995. Fuzzy logic prioritization of failures in a system - failure mode, effects and criticality analysis. Reliability Engineering and System Safety, 50, 203-213.

[18] Guimaraes, A., and Lapa, C. M. 2006. Hazard and operability study using approximate reasoning in light-water reactors passive systems. Nuclear Engineering and Design, 236, 1256-1263.

[19] Kangari, R., and Riggs, L. S. 1989. Construction risk assessment by linguistics. IEEE Transaction on Engineering and Management, 36, 126131.

[20] Stamatis, D. H. 1995. Failure mode and effect analysis - FMEA from theory to execution. New York: ASQC Quality Press.

[21] Chen, L., Liu, L., and Liu, N. 2013. Risk evaluation approaches in failure mode and effects analysis: A literature review. Expert Systems with Applications, 40, 828-838.

[22] Josie, Ali, S., Salty, Prinaz. 2010. Environmental hazards analysis of polyethylene unit of Ariazul Polymer Complex Assaluyeh by FMEA method, 1st National Conference on Health, Environment and Sustainable Development, Islamic Azad University, Bandar Abbas Branch.

[23] Yazdi, T., and Layla. 2011. Environmental risk assessment of air pollution in Anbar, Yazd oil distribution company and air pollution zoning using GIS, Second Conference on Environmental Planning and Management.

[24] Ghaderi, Abdolrahim, Ranjbar, Ali, Ghaderi, and Abbas. 1394 Environmental Impact Assessment of Oil and Gas Refineries, 4th International Conference on Environment, Energy and Biological Défense.

[25] Amini, Elham, Abargarmani, A., Heshmat. 2011. Types of Risk Assessment Methods and Analysis of Error Modes and their Effects Based on the FMEA Method, The First National Conference on Health, Safety and Environment, Islamic Azad University, Mahshahr Branch.

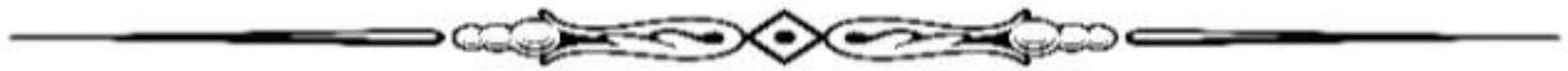

